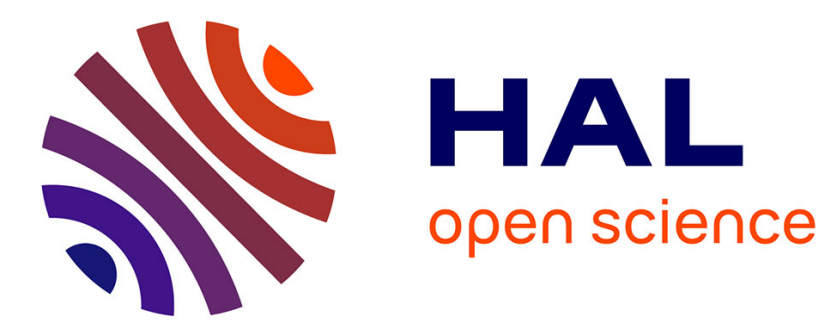

\title{
On the imprecision of consumer's spatial preferences
}

Claude Ponsard

\section{To cite this version:}

Claude Ponsard. On the imprecision of consumer's spatial preferences. [Research Report] Institut de mathématiques économiques (IME). 1978, 22 p., figures, bibliographie. hal-01527173

\section{HAL Id: hal-01527173 \\ https://hal.science/hal-01527173}

Submitted on 24 May 2017

HAL is a multi-disciplinary open access archive for the deposit and dissemination of scientific research documents, whether they are published or not. The documents may come from teaching and research institutions in France or abroad, or from public or private research centers.
L'archive ouverte pluridisciplinaire HAL, est destinée au dépôt et à la diffusion de documents scientifiques de niveau recherche, publiés ou non, émanant des établissements d'enseignement et de recherche français ou étrangers, des laboratoires publics ou privés. 


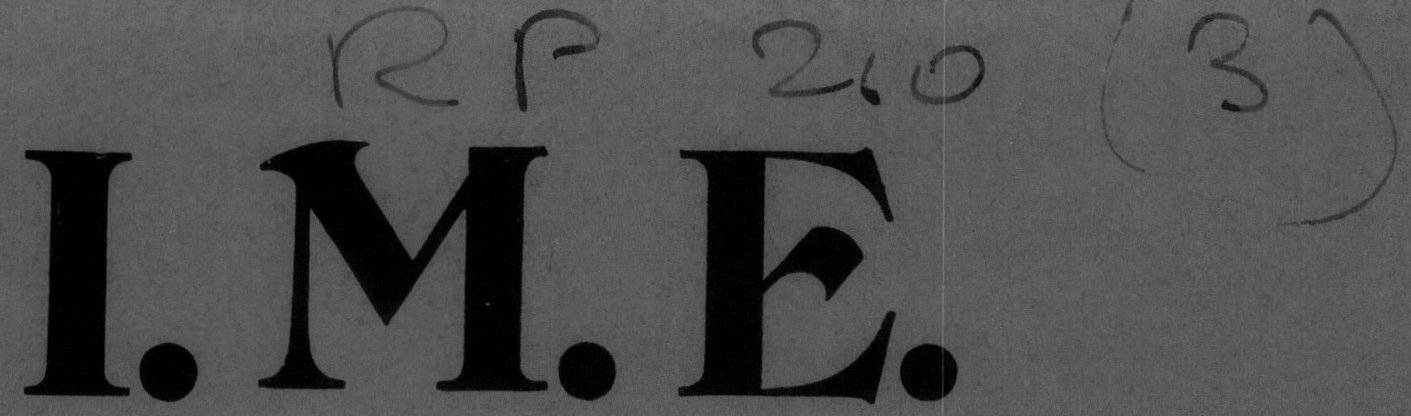

ÉQUIPE DE RECHERCHE ASSOCIÉE AU C.N.R.S.

DOCUMENT DE TRAVAIL

$N^{\circ} 26$

ON THE IMPRECISION OF CONSUMER'S SPATIAL PREFERENCES

Claude PONSARD

Apri1 1978

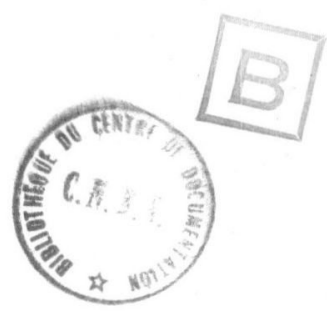

INSTITUT DE MATHÉMATIQUES ÉCONOMIQUES

UNIVERSITÉ DE DIJON

FACULTE DE SCIENCE ÉCONOMIQUE ET DE GESTION

4, BOULEVARD GABRIEL - 21000 DIJON 
$N^{\circ} 26$

ON THE IMPRECISION OF CONSUMER'S SPATIAL PREFERENCES

Claude PONSARD

April 1978

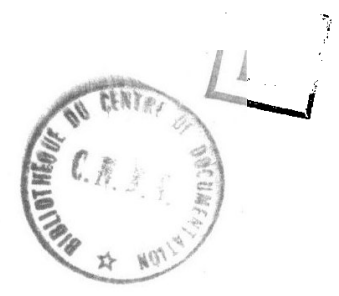

This study is to be presented as a paper at the European Symposium of the "Regjonal. Science Association" Fribourg (Switzerland) $29^{\text {th }}$ August - $1^{\text {st }}$ September 1978.

It was translated into English by Margaret CHEVAILLIER 
The author wishes to thank his colleagues and friends from the Academy of Economics of Poznan, from the Urban and Regional Science Unit of the Catholic University of Louvain-la-Neuve and from the Institute of Mathematical Economics of the University of Dijon with whom he has had many fruitful discussions. He alone remains responsible for the ideas expressed in this paper. 


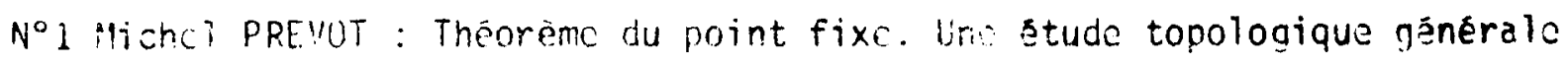
(juin 1974)

$N^{\circ} 2$ Danial LEBLANC : L'introduction des consommations intermédiaires dens

lo modèto de LEFEBER (juin 1974)

$N^{\circ} 3$ Colette Bolyon : Spatial Equilibrium of the Sector in Quasi-Parfect Competition (septamber 1974)

$N^{\circ} 4 \mathrm{Claude}$ PONSRON : L'imprécision at son traitement en analyse economique (septembre $19 \% 4$ )

N०5 Claude PONSARO : Economic urbaine et especes métriques (s aptembre 1974) :. 6 ilichol PREVOT : Convioxite (mars 1975)

No7 Cladd PONSARE : Contribution à une theor ia des espaces économiques imprẹcis (avril 1975)

N०8 Aine VOGT : Analyse factoricllo en composartcs principales d'un caracti ri de dimension-n (juin 1975)

$N^{\circ} g$ lacques THISSE et lacky PERREUR : Relation hetween the Point of 'aximum Profit and the Point of Minimum Total Transportation Cost : A Restatement (juillot 1975)

$N^{\circ} 10$ Bernard FUSTIER : L'attraction des points de vante dans des espaccs précis ct imp̣récis (juillet 1975)

$N^{\circ} 11$ Régis DELOCHE : Théoric des sous-enscmbles flous et classification an analysc économique spatialc (juillet 1975)

No12 Gérard LASSIBILLE ct Catherine P,NRRCN : inalyso multicritère dans un context: imprācis (juillet 1975)

$N^{\circ} 13$ Clzude PONSARD : On the Axiomatization of Fuzzy Subsets Theory (july1975) $N^{\circ} 14$ Michol PREVOT : Probability Calculation and Fuzzy Suhsets Theory (august 1975) 
if 15 Claude PONSRRD : Hierarchic des placis centrales et graphes $\Phi$-flous (avri? 1975)

No 16 Jcan-Pierre RURAY ct Gérard DLRU introduction à la théorie das espaces multiflous (avril 1976)

$N^{\circ} 17$ Rniand LANTNER, Bernard PETITJE simuiation du circuit. Economique (hoût 1970)

N! 18 Claudc PONSRRD : Esquisse de simulation d'une économic rínionale : l'apport de la théorie des systèmes flous (septerere 1976)

No 19 larie-Claude PICHERY : Les systèmes complets dr. fonctions do damanda (avril 1977)

H० $^{\circ} 20$ Gérard LASSIBILLE ct filain MINGGiT : L'estimation de modèles à vi.ui:: dépendante dichotomique - La silection univarsicir. ot la réussite en première année d'iconomic (avril 1977)

$N^{\circ} 21$ Claude PONSARD : La régicn en analy'se spatialc (mai 1977)

$N^{\circ} 22$ Dan RALESCU : Atstract Models for Systams identification (juin igh?

$N^{\circ} 23$ J.lAARCHAL et F.POULON : Multiplicateur, graphes et chaines de Markov (décembre 1977).

$N^{\circ} 24$ Pietra BALESTRA : Determinant and inverse of a sum of matrices with applications in economics and statistics (avril 1978) $N^{\circ} 25$ Bernard FUSTIER : Etude empirique sur la notion de région homogène (avril 1978) 
Table of Contents.

0 - Introduction

1 - Choice in imprecise preference structures

2 - The continuity of preferences and imprecise utility.

3 - Conclusion

4 - Appendix

5 - Bibliography. 
0 - INTRODUCTION.

01 - Faced with a set of needs of different intensities and which he perceives more or less indistinctly, a consumer is not normally capable of selecting among the elements belonging to his set of possible consumptions, those he prefers or is indifferent to and those from which he is likely to derive utility.

Moreover the goods and services are attainable to different degrees (available in supply space) and his knowledge is perfect only in border-line cases with the result that his world is generally imprecise. Even someone with an exceptional gift for discrimination is not capable of formulating for any pair of goods, his preference or indifference according to binary logic.

02 - The purpose of this paper is to remove the usual assumption (which it must be added is essential to the classical theory of consumer behaviour) that the consumer is capable of discriminating perfectly between different goods. It is well known that his behaviour, like any human behaviour, is by nature imprecise.

Furthermore, unlike the usual theory, the goods capable of satisfying needs are assumed to be scattered in a supply space and transportable. The agent is located at a given point of demand.

03 - Notation:

Only ordinary (non fuzzy) mathematical concepts are underlined. For example $A \subset \underline{X}$ is a fuzzy subset of the $\underline{X}$ referential. However, when there can be no possible ambiguity, this convention will be dropped.

04 - A supply space is characterized by a set, denoted $\underline{L}$, of $m$ points of supply, denoted $\underline{I}: \underline{L}=\{\underline{1} p\}, p=1, \ldots, m$. The set $\underline{\underline{L}}$ is at most countable.

A point of demand is chosen (location of the consumer), denoted $11^{\circ}$ 
The set of $n$ located goods is represented by a vector, denoted $\underline{x}: \underline{x}=\left[\underline{x}_{i}^{p}\right], i=1, \ldots, n$. The quantities of the goods are denoted $\underline{x}_{i}^{p}$.

05 - From the set of goods $\underline{X}$ the set of possible consumptions, denotes $\underline{K}$, is defined. An element of $\underline{K}$ is a vector whose components are the quantities of goods $\underline{x}_{i}^{p}$ the consumer must choose. A vector of $\underline{k}$ is denoted $\left[h_{k}\right]$. One writes therefore: $\underline{k}=\left\{\left[\underline{h_{k}}\right]\right\}, h=1, \ldots, g, \ldots, j, \ldots, 1, \ldots,{ }_{i} \underline{k}$ is assumed to be countable. A consumptions vector is written $\left.h_{k}=\left[\underline{h}_{\underline{x}}\right]_{j}\right]$. Careful distinction must be made between the set of possible consumptions and the supply space of goods. Goods being mobile, the set of possible consumptions is defined at point $\underline{I}_{1}$ and is dissociated from the supply space. It should be noted that the expression"consumptions space" which is so often use should not lead to any confusion: it describes a set with given properties.

06 - Taking these definitions as a starting point, firstly a general study will be made of the structures of spatial preference in an imprecise context. Next, the particular properties will be introduced. These properties must be united within this analytical framework in order to define a behaviour of attainable choice. Then the conditions which guarantee the existence of a completely preordered topological space are imposed in order to verify that the consumer's imprecise behaviour is coherent. Finally these conditions permit us to define the existence and continuity of a fuzzy utility (a numerical representation of the imprecise preference). 
1 - CHOICE IN IMPRECISE PREFERENCE STRUCTURES.

11 - The consumer draws a comparison between any two complexes of goods, $g_{k}$ and $j_{k}$ at a more or less high level of preference or indifference. This level expresses the imprecision of his comparison.

Hence a fuzzy binary relation, denoted $\boldsymbol{R}$, between the elements of $\underline{k}^{2}$, is defined:

$g_{k} \Re^{j_{k}}=\left\{\left({ }^{g_{k}},{ }_{k}\right), \mu_{\Omega} ; \forall g_{k} \in \underline{k}, \forall j_{k} \in \underline{k}, \mu_{\Omega}\left({ }^{g_{k}},{ }^{j} k\right) \in \underline{M}\right\}$

where $\mu_{\Omega}\left({ }^{g} k, j_{k}\right)$ denotes the level of preference or indifference between the two complexes and $\underline{M}$ is a completely ordered membership set. A non numerical set suffices.

In other words, to each given preference-indifference system, a fuzzy subset, denoted $K$, is associated. $K$ is an element of the set of applications from $\underline{K}^{2}$ to $\underline{M}$, of the type:

$k=\left\{\left(g_{k}, j_{k}\right), \mu_{k} ; \forall g_{k} \in \underline{k}, \forall j_{k} \in \underline{k}, \mu_{k}\left(g_{k}, j_{k}\right) \in \underline{M}\right\}$

12 - The structure $(\underline{K}, \boldsymbol{R})$ is called an imprecise individual preference-indifference structure. It is broken down into two structures denoted respectively $(K, \zeta)$ and $(K, \sim)$ according to whether the relation $\mathcal{R}_{\text {is a strict fuzzy }}$ preference relation or a fuzzy indifference relation.

121 - The consumer prefers more or less a complex $g_{k}$ to a complex ${ }^{j} k$. One writes $\mu_{\Omega}\left({ }^{\left.g_{k},{ }^{j} k\right)}>\mu_{\Omega}\left({ }^{j}, g_{k}\right) \cdot \mu_{\Omega}\left({ }^{g_{k},{ }^{j}}\right)\right.$ will be called the degree of strong preference for $g_{k}$ relative to ${ }^{j} k$ and $\mu_{\Omega}\left({ }_{k}, g_{k}\right)$ the degree of weak preference for ${ }^{j} k$ relative to $g_{k}$.

The structure $(\underline{K}, \zeta)$ has the property of antisymetry as defined by KAUFMANN (7, Vol.1, page 105) since $\forall\left({ }^{g_{k}}, j_{k}\right) \in \underline{k}^{2}, g \neq j$, one has:

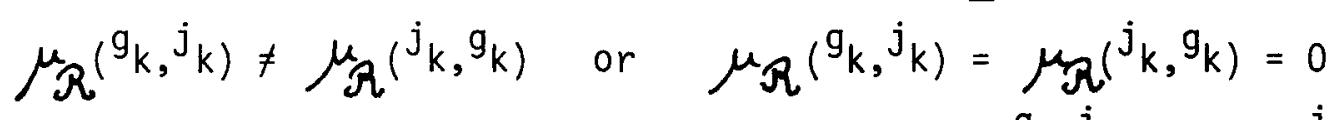

Nevertheless, the assumption that $\mu_{\pi}\left({ }^{g_{k}},{ }^{j} k\right)=\mu_{\Omega}\left({ }^{j}, g_{k}\right)=0$

will only be introduced in paragraph (1222) within the framework of the definition of the indifference structure, where it will be taken as a particular case of fuzzy symmetry. In the present case it is important for 
the structure $(\underline{k}, \gamma)$ that $\forall\left({ }^{g},{ }^{j} k\right) \in \underline{k}^{2}, g \neq j, \oiint\left(g_{k},{ }^{j} k\right)$ such that $\mu_{\Re}\left({ }^{\left.g_{k},{ }^{j} k\right)}=\mu_{\Re}\left({ }^{j},{ }^{g_{k}}\right) \neq 0\right.$.

Remark.

In the classical theory of consumer behaviour, one has:

$$
\forall\left({ }^{g},{ }^{j} k\right) \in \underline{k}^{2}, g \neq j: \mu_{\Omega}\left({ }^{g} k,{ }^{j}\right)=1 \Longleftrightarrow \mu_{\Omega}\left({ }^{j} k,{ }^{g}\right)=0
$$

The consumer prefers or does not prefer one complex to another.

122 - The consumer can be more or less indifferent between $g_{k}$ and ${ }^{j_{k}}$. Thus an indifference structure can be defined $(K, \sim)$. One has:

$$
\forall\left({ }^{g}, j_{k}\right) \in \underline{k}^{2}, g \neq j: \mu_{\Omega}\left({ }^{g_{k}},{ }^{j} k\right)=\mu_{\Omega}\left({ }^{j} k,{ }^{g_{k}}\right) \text {. }
$$

By definition, the structure $(\underline{K}, \sim)$ has the property of fuzzy

symmetry.

Remarks.

(1221): Classical theory only retains the special case in which these membership functions equal 1 .

(1222): The degree of indifference can equal zero. In which case, the complexes of goods are considered to be useless.

123 - The imprecise preference-indifference structure $(\underline{K}, \mathfrak{R})$ is complete since $\mu_{\Omega}\left({ }^{g} k,{ }_{k}\right)=0$ if $\left({ }^{g_{k}} ;{ }^{j_{k}}\right)=\emptyset$ (non comparability assumption). The comparability axiom has not been introduced here and the "situation of non comparability does not create any particular problems as it does in the classical theory of consumer behaviour.

13 - Now if the fuzzy relation $\mathcal{R}$ is reflexive and transitive, the set $\underline{k}$ has a fuzzy complete preordering structure.

131 - We have first: $\forall\left({ }^{g_{k}},{ }^{g_{k}}\right) \in \underline{k}^{2}: \mu_{\Omega}\left({ }^{g_{k}},{ }{ }_{k}\right)=1$ The relation $\Re_{\text {is }}$ reflexive. 
132 - Next if the preference for $g_{k}$ relative to ${ }^{1} k$ is at least equal to the maximum for ${ }^{j_{k}}$ of the smaltest values of the preference for ${ } k$ relative to ${ }^{j_{k}}$ and for ${ }^{j_{k}}$ relative to ${ }_{k}$, then the relation $\Re$ is transitive. One has:

$$
\begin{aligned}
& \forall\left({ }_{k},{ }^{j} k\right),\left({ }^{j} k,{ }^{1} k\right),\left({ }^{g} k,{ }^{1} k\right) \in \underline{k}^{2}:
\end{aligned}
$$

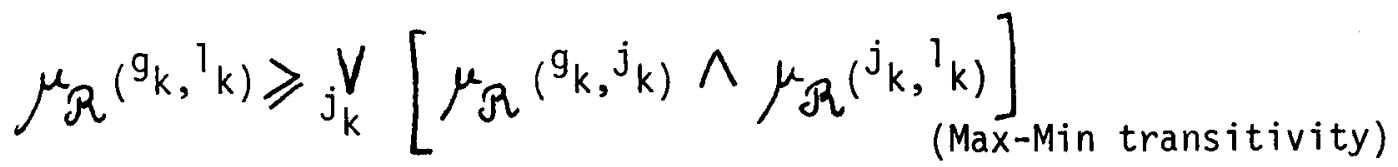

Remarks.

(1321) We have a property of weak transitivity.

(1322) Replacing operator Max and operator Min (which are equivalent boolean operators) by boolean addition and boolean multiplication we obtain the same formulation in the classical theory.

133 - Finally, from 123 , we have the property of completness.

14 - Consider a fuzzy individual preference structure written ( $\underline{k}, \underline{t})$. It does not have the properties which guarantee the consistency of the consumer's preferences. The reflexivity and Max-Min transitivity properties do not suffice to ensure that indifference is congruent to the right (resp. to the left) with strict and strong preference, contrary to the result obtained when using a theorem from the classical theory [3,page 36] (see an example,Appendix 41).

It follows that the structure $(K, \sim)$ is not an equivalence structure. In fuzzy preordering, all the non fuzzy subsets, denoted $\underline{k}_{r}, \underline{k}{ }_{r} \subset \underline{k}$, $r=1, \ldots, h$, such that:

$\forall\left(g_{k},{ }_{k}\right) \in \underline{k}_{r}^{2}, \mu_{\Omega}\left({ }^{g_{k}},{ }^{j} k\right)=\mu_{\Omega}\left({ }^{j}, g_{k}\right)$

form similarity sub relations, denoted $k_{s}, k_{s} \subset \underline{K}, s \in \underline{I}, \underline{I} \subset \underline{M}$. We know that a similarity subrelation is maximal if it is not a similarity subrelation of any other subrelation of the same kind in the relation being examined.

The combined properties of fuzzy symmetry, reflexivity and Max Min transitivity do not necessary imply that the maximal subrelations are disjoint.

141 - Two conditions must be imposed on the structure $(\underline{k}, \geqslant)$ so that the maximal similarity subrelations form similarity classes.

Consider two maximal similarity relations: 
10

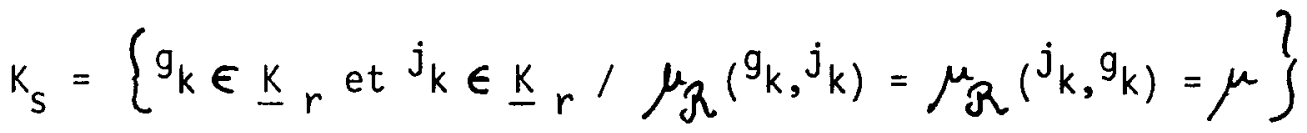

$$
\begin{aligned}
& k_{s^{\prime}}=\left\{{ }^{1} k \in \underline{k}_{r^{\prime}} \text { et }{ }^{m_{k} \in \underline{k}_{r^{\prime}} / \mu_{\Omega}\left({ }^{1} k,{ }^{m_{k}}\right)=\mu_{\Omega}\left({ }^{m_{k}},{ }^{1} k\right)=\mu} \mu^{\prime}\right\}
\end{aligned}
$$

aves $\mu>\mu^{\prime}$

1411 - Axiom (1): Strong preferences for the indifferent complexes $g_{k}$ and $j_{k}$ relative to the indifferent complexes $l_{k}$ and $m_{k}$ are at least equal to the level of indifference between the complexes $g_{k}$ and $j_{k}$

Hence: $\mu_{\Omega}\left({ }^{g} k,{ }^{1} k\right) \geqslant \mu$

$$
\text { and } \begin{aligned}
\mu_{R}\left({ }^{j_{k},}, k\right) & \geqslant \mu \\
\mu_{\Omega}\left({ }^{j_{k}},{ }^{m_{k}}\right) & \geqslant \mu
\end{aligned}
$$$$
\mu_{\Omega}\left({ }^{g_{k}},{ }^{m} k\right) \geqslant \mu
$$

1412 - Axiom (2): The weak preferences for the indifferent:

complexes ${ }^{l_{k}}$ and ${ }^{m_{k}}$ relative to the indifferent complexes $g_{k}$ and ${ }^{j} k$ are strictly equal to the level of indifference between the complexes ${ }^{1} k$ and $m_{k}$ Hence $\mu_{R}\left({ }^{1} k,{ }_{k}\right)=\mu^{\prime} \quad$ and $\mu_{R}\left({ }^{m_{k}},{ }^{g_{k}}\right)=\mu$.

$$
\mu_{\Omega}\left({ }^{1} k,{ }^{j} k\right)=\mu^{\prime} \quad \mu_{R}\left({ }^{m} k,{ }^{j} k\right)=\mu^{\prime}
$$

Remarks.

(1413) Only axiom (2) is a constraint

(1414) Axiom (2) implies:

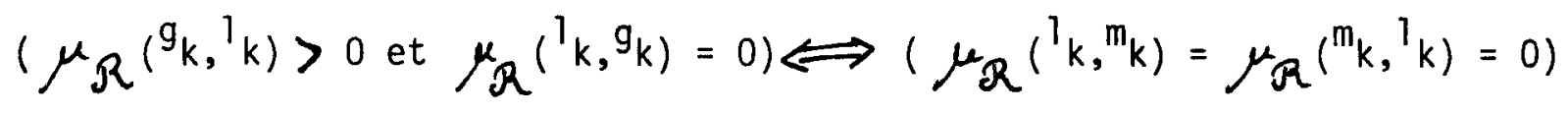

142 - We can verify immediately that these conditions satisfy the proparty of MaxiMin transitivity since by construction $\mu_{\Omega}\left({ }^{g_{k}},{ }^{1} k\right)$ is greater or equal to the maximum for $j_{k}$ of the smallest value of the preference levels between, on the one hand, the complexes $g_{k}$ and $j_{k}$ and, on the other hand, the complexes $j_{k}$ and $T_{k}$.

143 - It is easy to prove that the structure $(\underline{K}, \sim)$ is a fuzzy equivalence structure if and only if it satisfies axioms 1 and 2 .

Indeed, a pair of complexes $g_{k}$ and ${ }^{j_{k}}$ belong to a same similarity subrelation if and only if $\mu_{\Re}\left({ }^{g_{k}},{ }_{k}\right)=\mu_{\Re}\left({ }^{j_{k}}, g_{k}\right)=\mu$. It follows from this that all similarity subrelations which have symmetrical pairs of elements and the same membership functions $\mu$ are identical and form a maximal similarity subrelation. From axioms (1) and (2), the pairs $g_{k}$ and ${ }^{1} k$ are such that

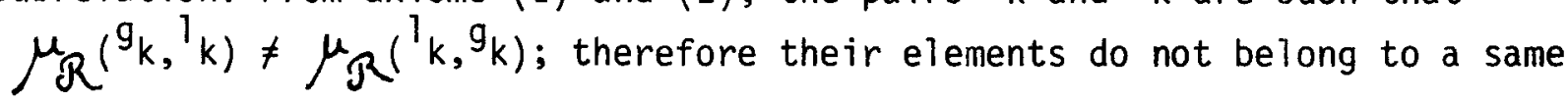


maximal similarity subrelation: the maximal similarity subrelations are disjoint and form similarity classes.

Conversely, if any pair of complexes $\left({ }^{g} k,{ }^{1} k\right)$ satisfies the axioms (1) and (2) its elements do not form a similarity subrelation since

$\mu_{\Omega}\left({ }^{g_{k}},{ }_{k}\right) \neq \mu_{\Omega}\left({ }^{1} k,{ }_{k}\right)$. Therefore they can only belong to different maximal similarity subrelations and the maximal similarity subrelations form similarity classes.

$\underline{K} / \sim$ denotes the quotient set.

144 - Conditions (1) and (2) give the structure $(\underline{k}, \geqslant)$ the properties of congruence to the right and left of indifference relative to strong preference.

We check that: $\forall\left({ }^{g} k,{ }_{k},{ }^{m_{k}} k \in \underline{k}^{3}\right.$ :

$$
\begin{aligned}
& {\left[\mu_{R}\left({ }^{g_{k}},{ }^{1} k\right)>\mu_{R}\left({ }^{l} k,{ }_{k}\right)\right] \text { et }\left[\mu_{\Omega}\left({ }^{l} k,{ }^{m_{k}}\right)=\mu_{\Omega}\left({ }^{m_{k}},{ }^{l} k\right)\right]} \\
& \Longrightarrow \mu_{R}\left({ }^{g_{k}},{ }^{m_{k}}\right)>\mu_{R}\left({ }^{m},{ }_{k}\right)
\end{aligned}
$$

Indeed

$$
\left[\mu_{R}\left(g_{k},{ }^{l} k\right)>\mu_{R}\left({ }^{1}, g_{k}\right)\right] \text { et }\left[\mu_{R}\left({ }^{1} k,{ }^{m}\right)=\mu_{\Omega}\left({ }^{m} k,{ }^{1} k\right)\right]
$$

$\Longrightarrow\left[\mu_{\Omega}\left({ }^{g_{k}},{ }^{1} k\right) \geqslant \mu_{\Omega}\left({ }^{1} k,{ }^{g_{k}}\right)\right.$ et $\mu_{\Omega}\left({ }^{1} k,{ }^{m_{k}}\right) \geqslant \mu_{\Omega}\left({ }^{\left.m_{k},{ }^{1} k\right)}\right]$

From the property of transitivity we have $\mu_{\Omega}\left({ }^{g} k,{ }^{m} k\right) \geqslant \mu_{\Omega}\left({ }^{m_{k}},{ }^{g_{k}}\right)$ Assuming that $\mu_{\Omega}\left({ }^{m} k,{ }_{k}\right)=\mu_{\Omega}\left({ }^{g} k,{ }^{m_{k}}\right)$ leads us to a contradiction. From the transitivity property of the indifference relation, we have:

$\mu_{\mathcal{R}}\left({ }^{l} k, g_{k}\right)=\mu_{\boldsymbol{R}}\left({ }^{g_{k}},{ }^{l} k\right)$, i.e. $\mu_{\boldsymbol{R}}\left({ }^{l} k,{ }^{g} k\right) \geqslant \mu_{\Omega}\left({ }^{g_{k}},{ }^{1} k\right)$ which contradicts

$\mu_{R}\left({ }^{g},{ }^{l} k\right)>\mu_{R}\left({ }^{l} k,{ }_{k}\right)$. Hence, we have $\mu_{R}\left({ }^{g} k,{ }^{m_{k}}\right)>\mu_{R}\left({ }^{m_{k}},{ }^{g_{k}}\right)$.

The congruence to the right of indifference relative to strong preference is verified. By a similar reasoning the property of congruence to the left can be established (see example, Appendix 42).

145 - The $r$ - uples ordered such that:

cq $\left({ }^{g} k,{ }^{1} k\right)=\left({ }^{g} k={ }_{q} k_{1},{ }_{q}^{j} k_{2}, \ldots,{ }_{q}^{h_{k}}, \ldots,{ }_{q} k_{r}={ }^{1} k\right)$ where $t=1, \ldots, r$, ${ }_{q} k_{t} \in \underline{k}$ and the condition $\forall\left({ }_{q}^{g} k_{t},{ }_{q}^{j} k_{t+1}\right): \mu_{R}\left({ }_{q}^{g} k_{t},{ }_{q}^{j} k_{t+1}\right)>0$, where $t=1, \ldots, r-1$ are called "paths from ${ }^{9} k$ to $k$ ", denoted cq $\left({ }^{9} k,{ }^{l} k\right)$ each path having an index $q(q=1, \ldots, s)$. 
defined by:

A value denoted $v_{q}\left(g_{k}, l_{k}\right)$ is associated to every path. It is

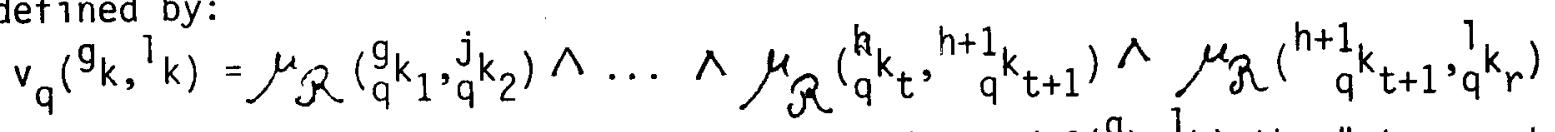

In the set of paths valued in this way and denoted $c\left({ }^{g} k,{ }^{1} k\right)$ the "strongest path"

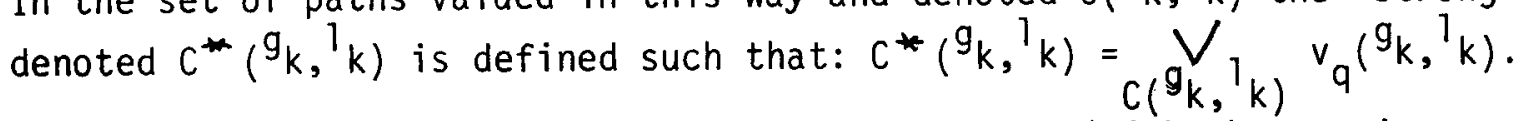

Since the fuzzy preordering is reducible (with the meaning used in the theory of fuzzy binary relations), the similarity classes form a fuzzy ordering relation if werstrongest path, unique by construction, from one class to another. Indeed the relation formed between the similarity classes is by necessity antisymetric, otherwise they would not all be disjoint two by two. 15 - We are now in a position to define an imprecise behaviour of attainable choice.

151 - Consider a fuzzy individual preference structure $(\underline{K}, \xi)$ and $\mathrm{J} \subset \underline{K}$ a fuzzy part of $\underline{K}$.

A consumption $g_{k} \in J$ is optimal relative to $J$ if and only if $g_{k}$ is a maximal element of the structure $(J, \geqslant)$ i.e. if and only if:

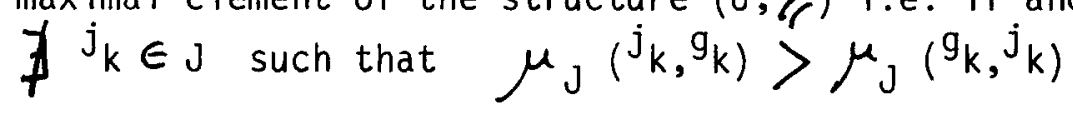

A consumption $g_{k} \in J$ is a greater element of $J$ if and only if $g_{k}$ is a maximum of the structure $(J, \geqslant)$ i.e. if and only if:

$$
\forall j_{k} \in J: \mu_{j}\left({ }^{g_{k}},{ }^{j} k\right) \geqslant \mu_{j}\left({ }_{k},{ }^{g_{k}}\right)
$$

A set of better elements of $\mathrm{J}$ is denoted $\mathrm{S}(\mathrm{J})$ and will be called the set of imprecise choices.

152. Introducing ther $s(J)$ enables us to formulate the consumer's behaviour which is associated with the structure $(\underline{K}, \underline{l})$. The application $S$ of all the fuzzy parts of $K$ in $K$ itself is defined such that:

$$
\begin{aligned}
& s: \bar{P}(K) \longmapsto \underline{K} \\
& \mathrm{~J} \longmapsto \bar{s}(J)=\left\{g_{k} \in J ; \forall j_{k} \in J ;\right. \\
& \left.\mu_{j}\left({ }^{g_{k}},{ }^{j} k\right) \geqslant \mu_{J}\left({ }^{j} k, g_{k}\right)\right\}
\end{aligned}
$$

The choice is still possible since application $S$ is defined everywhere and the imprecise behaviour of choice is attainable. 


\section{2 - THE CONTINUITY OF PREFERENCES AND IMPRECISE UTILITY}

21 - At this point we must specify what conditions are to be imposed on the fuzzy individual preference structure $(\underline{K}, \underline{l})$ to ensure that a completely preordered topological space exists and that the consumer's imprecise behaviour is consistent. Finally, these conditions enable us to guarantee the existence and continuity of a fuzzy utility.

From now on, we choose $\underline{M}=[0,1]$ and if:

$\mu_{\Omega}\left({ }^{g_{k}},{ }_{k}\right)=\mu_{\Omega}\left({ }^{j}{ }_{k},{ }_{k}\right)=\mu$,

we assume that: $\mu_{k}\left({ }^{g_{k}}\right)=\mu$ and $\quad \mu_{k}\left({ }^{j}\right)=\mu$

where $K$ is a fuzzy subset of $\underline{K}$ associated with a system of imprecise preference such that:

$$
\begin{aligned}
& k=\left\{g_{k}, \mu_{k} ; \forall g_{k} \in \underline{k}, \mu_{k}\left({ }_{k}\right) \in[0,1]\right\} \\
& u_{k}\left({ }^{g}\right) \text { and } \mu_{k}\left({ }_{k}\right) \text { will be called the relative degrees of }
\end{aligned}
$$
preference for one complex of goods compared to the others.

211 - A fuzzy topology on $\underline{k}$, denoted $\boldsymbol{Z}$, is defined.

Let $\mu_{K}\left({ }^{g}\right)$ be the relative degree of preference for the complex $g_{k}$ and $\left(\mu_{k}\left(h_{k}\right)\right)_{n}, n \in \mathbb{N}$, an infinite sequence of relative degrees of preference for the complexes of goods which tend to $\mu_{K}\left({ }^{\circ} \mathrm{k}\right)$, where ${ }^{\circ} \mathrm{K}$ is an element of $\underline{K}$, when $n$ tends to infinity.

If for any integer $n,\left(\mu_{K}\left({ }^{h_{k}}\right)\right)_{n}$ is at most as great (resp. at least as great) as $\mu_{K}\left({ }^{g} k\right)$, then $\mu_{K}\left({ }^{\circ} k\right)$ is at most as great (resp. at least as great) as $\mu_{K}\left({ }^{g}\right)$, which means that ${ }^{\circ} k$ is at most as preferred (resp. at least as preferred)as ${ }^{g} k$.

In other words, for every $g_{k}$ and for every $h_{k}$ in $\underline{k}$ the fuzzy subsets:

and

$$
k^{*}=\left\{h_{k} \in \underline{k} / \mu_{k}\left({ }^{h_{k}}\right) \leqslant \mu_{k}\left({ }^{g} k\right)\right\}
$$

$$
k_{*}=\left\{h_{k} \in \underline{k} / \mu_{k}\left({ }^{h_{k}}\right) \geqslant \mu_{k}\left({ }^{g}\right)\right\}
$$

are closed in $\mathrm{K}$. 
The topological space $(\underline{k}, \geqslant, \boldsymbol{Z})$ is said to be an imprecise preference space that is the preferences are continuous for $\zeta$ if and only if:

$$
\forall g_{k} \in \underline{k}, k^{*} \in \mathcal{Z} \text { and } k_{*} \in \boldsymbol{Z} \text {. }
$$

212 - Consider a given system of individual imprecise preference with which a fuzzy subset $K$ is associated. We shall now indicate which convexity condition must be imposed $v_{v}$ ih order to guarantee that the structure $(\underline{k}, \forall, Z)$ is a completely preordered topological preference space.

2121 - A fuzzy subset $V$ is convex (weak convexity) if and only if the membership function is quasi-concave:

$$
\begin{aligned}
& \forall{ }^{g_{k}} \in \underline{k}, \forall j_{k \in \underline{k}}, g_{k} \neq j_{k}, \mu_{k}\left({ }_{k}\right) \geqslant \mu_{k}\left({ }^{j}\right) \\
& \Longrightarrow \forall \alpha \in]_{0,1}\left[, \mu_{k}\left(\alpha^{g_{k}}+(1-\alpha)^{j_{k}}\right) \geqslant \mu_{k}\left({ }^{j_{k}}\right)\right.
\end{aligned}
$$

If the individual is indifferent to or prefers the complex ${ }^{g_{k}}$ to complex $j_{k}$, to the respective degrees $\mu_{k}\left({ }^{g}\right)$ and $\mu_{k}\left({ }^{j_{k}}\right)$, then the membership function of any weighted average with positive coefficients for $g_{k}$ and $j_{k}$ is greater or equal to the membership function of the complex $j_{k}$.

Remark.

$$
\begin{aligned}
& \underline{k} \text { is a convex set. Indeed, } \forall g_{k} \in \underline{k}, \forall j_{k} \in \underline{k} \text {, } \\
& \forall \alpha \in \overline{]} 0,1\left[:\left(\alpha^{g_{k}}+(1-\alpha)^{j_{k}}\right) \in \underline{k}\right.
\end{aligned}
$$

2122 - The following preliminary result is needed to establish the existence of a completely preordered fuzzy topological space.

Let $(K, Z)$ be a fuzzy topological space. If $K, K \subset \underline{K}$ is closed in $(\underline{K}, \mathcal{Z})$ then $k$ contains the limit of all its convergent sequences.

Indeed, let $(X n)$ be a sequence of fuzzy parts of $K$, converging to a fuzzy subset $X_{0}$ of $\underline{K}$. By definition any neighbourhood $V\left(X_{0}\right)$ of $X_{0}$ countains fuzzy subsets of $\left(x_{n}\right)$ and hence of $k$, which means that $x_{0}$ is adherent to $k$, and therefore $x_{0} \subset K$, since $K$ is closed. 
15

2123 - UZAWA's result obtained within the framework of the classical theory may be generalized [5]

- Let $(\underline{k}, \underline{\zeta}, \boldsymbol{Z})$ be an imprecise preference space, $\underline{k}$ convex, if: $i$ - the fuzzy relation is complete and satisfies the convexity condition, ii - the fuzzy relation of strict preference is Max-Min transitive, then $(\underline{k}, \geqslant, Z)$ is a completely preordered topological preference space.

Remark.

UZAWA's theorem only holds if the (non fuzzy) relation satisfies the strong convexity condition (in the usual meaning of the word).

- Proof. The property of totality implies that of reflexivity. The fuzzy relation can be proved to be MaxiMin transitive by reduction ad absurbum.

Consider:

$$
\begin{aligned}
& \left({ }^{g} k,{ }^{j} k\right),\left({ }^{j} k,{ }^{1} k\right),\left({ }^{g_{k}},{ }^{l} k\right) \in \underline{k}^{2}: \\
& \mu_{\Omega}\left({ }^{g_{k}},{ }^{j_{k}}\right) \geqslant 1_{k}\left[\mu _ { \Omega } \left({ }^{\left.\left.g_{k},{ }^{1} k\right) \wedge \mu_{\Omega}\left({ }^{1} k,{ }^{j_{k}}\right)\right]},\right.\right. \\
& \mu_{\Omega}\left({ }^{j},{ }^{1} k\right) \geqslant g_{k}^{V}\left[\mu_{\Omega}\left({ }^{j},{ }_{k}\right) \wedge \mu_{\Omega}\left({ }^{g_{k}},{ }^{l} k\right)\right] \text {, }
\end{aligned}
$$

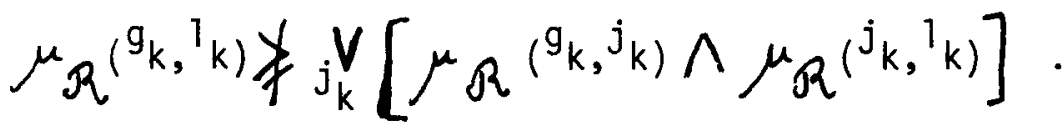

Since the fuzzy relation is complete, the last relation implies that:

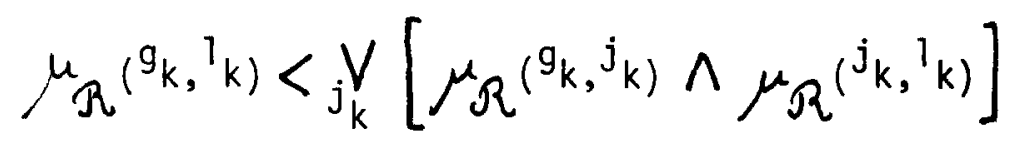

From which it follows that:

$$
\mu_{k}\left({ }^{g} k\right)<\mu_{k}\left({ }^{1} k\right) \quad(\text { see }(21)) \text {, ie. that } g_{k \in K^{*}} \text { (see (211)) }
$$

We can find $\left.\alpha^{*} \epsilon\right] 0,1[$ such that

$$
i-\mu_{k}\left(\alpha^{*} j_{k}+\left(1-\alpha^{*}\right)^{g_{k}}<\mu_{k}\left({ }^{1} k\right)\right.
$$


16

If not, for any $\alpha \epsilon] 0,1[$, we would have:

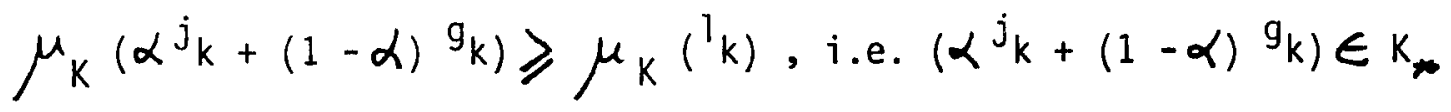

(see $(211))$.

$$
\text { Now, } u_{k}\left({ }^{g} k\right)=\lim _{\alpha_{n} \rightarrow 0} \mu_{k}\left(\alpha_{n} j_{k}+\left(1-\alpha_{n}\right) g_{k}\right) \text {. It follows }
$$

that since $K_{*}$ is closed, it contains the limit of its convergent sequences (see (2122)) which contradicts $g_{k} \in K^{*}$.

Since $\mu_{k}\left({ }^{g} k\right) \geqslant \mu_{k}\left({ }^{j} k\right)$, the convexity condition of imprecise preferences implies:

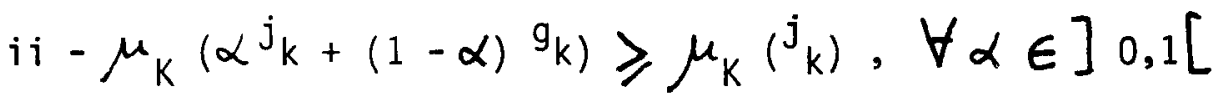

Finally, relations ( $i$ ) and ( $i$ ) and the MaxiMin transitivity property of imprecise preference imply that:

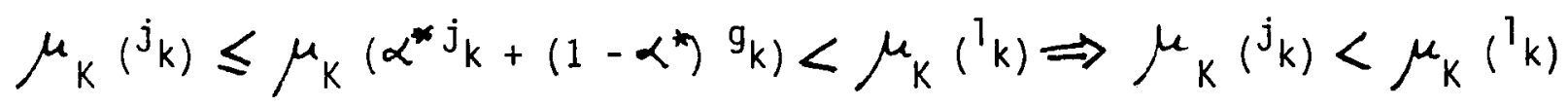

which contradicts the assumption:

$$
\mu_{\Omega}\left({ }^{j} k,{ }^{1} k\right) \geqslant \underset{g_{k}}{V}\left[\mu_{R}\left({ }^{j},{ }^{g_{k}}\right) \wedge \mu_{R}\left({ }^{\left.g_{k},{ }^{1} k\right)}\right]\right. \text {. }
$$

The fuzzy relation of imprecise preference is therefore MaxiMin transitive.

22 - Given a fuzzy structure of complete preference $(\underline{K}, \underline{\xi})$, by translating the qualitative description of the consumer's imprecision decision into a numerical formula we can define a fuzzy utility.

Indeed the function which relates the element of the interval $[0,1]$ associated with the corresponding degree of imprecise indifference to each similarity class $K_{S} \in \underline{K} / \sim$ has been built on to the quotient set $\underline{K} / \sim(\operatorname{see}(21))$. Let $f$ be that function

$$
\begin{aligned}
f: \frac{k}{k_{s}} / \sim \longmapsto & {[0,1] } \\
& \longmapsto
\end{aligned}
$$

The function is strictly increasing.

$$
\begin{aligned}
& \forall\left({ }^{g_{k}},{ }^{j_{k}}\right) \in \underline{k}_{r}^{2}, \forall\left({ }^{1} k,{ }^{m_{k}}\right) \in{\underline{k^{\prime}}}_{r^{\prime}} \text {, where } \mu_{\boldsymbol{R}}\left({ }^{g_{k}},{ }^{j_{k}}\right)=\mu, \mu_{\boldsymbol{\Omega}}\left({ }^{1}{ }_{k},{ }^{m_{k}}\right)=\mu^{\prime} \\
& \mu>\mu^{\prime}: f\left(k_{s}\right)>f\left(k_{s^{\prime}}\right) \text {. }
\end{aligned}
$$


If $\mathrm{g}$ is called the canon ic projection:

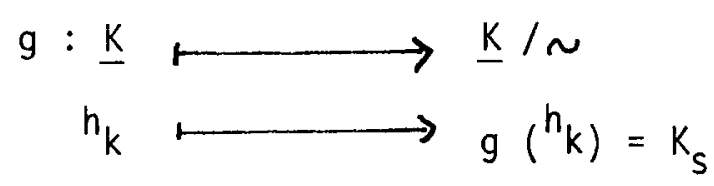

the o - composed function (in the usual meaning) $u=f \circ g$ is

written:

$$
\begin{aligned}
& u: \underline{k} \longmapsto \\
& h_{k} \longmapsto u\left(h_{k}\right)=f\left[g\left(h_{k}\right)\right]=f\left(k_{s}\right)=\mu .
\end{aligned}
$$

The function $u$, which associates an element of the interval $[0,1]$ with each element of the set $\underline{K}$ is called an imprecise utility function.

Complexes of goods belonging to a same similarity class produce the same degree of utility. If one similarity class contains a complex which is more or less preferred to a complex belonging to another similarity class, then the function associated with the first is greater than that associated with the second and conversely.

In other words, the function $u$ is such that:

$$
\begin{aligned}
& \forall g_{k} \in k_{s}, \forall j_{k} \in k_{s}:\left[\mu_{\Omega}\left(g_{k},{ }_{k}\right)=\mu_{\Omega}\left({ }^{j_{k}}, g_{k}\right)\right] \Rightarrow u\left({ }^{g_{k}}\right)=u\left({ }^{j_{k}}\right) \text {, } \\
& \forall g_{k} \in k_{s}, \forall{ }^{1} k_{s}:\left[\mu_{\Omega}\left({ }^{g_{k}},{ }^{1} k\right)>\mu_{\Omega}\left({ }^{1} k, g_{k}\right)\right] \Rightarrow u\left({ }^{g_{k}}\right)>u\left({ }^{1} k\right) .
\end{aligned}
$$

The fuzzy utility function allows the complexes of goods to be classified according to the order in which they are chosen by the consumer.

For a structure $(\underline{K}, \underline{\xi})$ a utility is any homomorphism from $(\underline{K}, \underline{\xi})$ to $([0,1], \geqslant)$.

221 - It is certain that a utility defined in this way exists, because we have here a case of the application of the theorem which states that a utility exists for a preference structure $(\underline{K}, \geqslant)$ if it is a completely preordered countable set [3, page 178]. 
222 - Finally, a continuous fuzzy utility is defined as any continuous homomorphism from $(\underline{K}, \geqslant, Z)$ to $([0,1], \geqslant, \mathcal{W})$ where $\mathscr{f}$ is the natura topology of $[0,1] \subset \mathbb{R}$. A fuzzy utility is continuous if and only if a utility for $(\underline{K}, \underline{l})$ which is continuous application from $(\underline{K}, \boldsymbol{Z})$ to $([0,1], \mathcal{N})$.

A similar result to that of the classical theory is found: a countable preference structure $(\underline{k}, \underline{\xi})$ for which a given utility exists, this utility is a continuous application from $(\underline{K}, \mathcal{F})$ to $([0,1], \mathbb{W})$ where $\mathcal{F}$ and $\mathcal{N}$ are the respective intrinsic topologies. 


\section{$3-\underline{\text { CONCLUSION }}$}

31 - The theory of fuzzy subsets proves relevant to the formalisation of the analysis of preferences and utility in a spatial world where consumers behaviour is imprecise.

The resulting economic theory is neither ordinal nor cardinal: we propose to call it "a valuable theory of preference".

32 - The assumption that the possible consumptions set is countable will have to be dropped. This is critical since the fuzzy subsets theory only has a weak theorem of separation at its disposal.

33 - The analysis of the structure of imprecise individual preference should be followed by a spatial theory of consumer demand in a fuzzy world, where C.I.F. prices and wealth constraints are introduced.

34 - The present model is static. In order to introduce time it will have to be developed further. For a constant system of imprecise preference structures, introducing incertitude would lead to a formulation in terms of probabilized fuzzy subsets. A dynamic analysis of the passage from one system to another would have to make use of differential topology. 


\section{4 - APPENDIX}

41 - A very simple example is given to illustrate proposition (14).

Consider the following structure $(\underline{k}, \geqslant)$

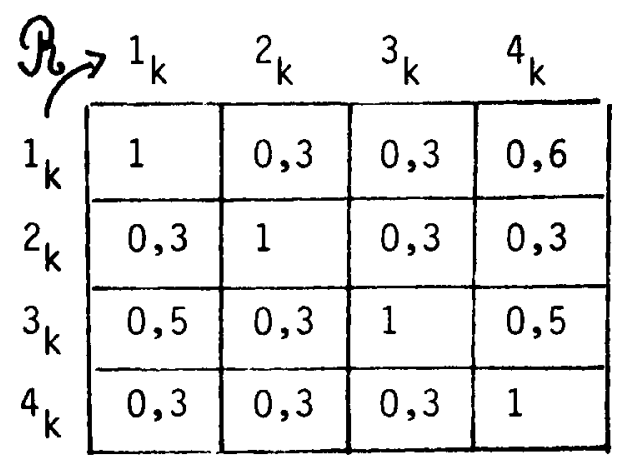

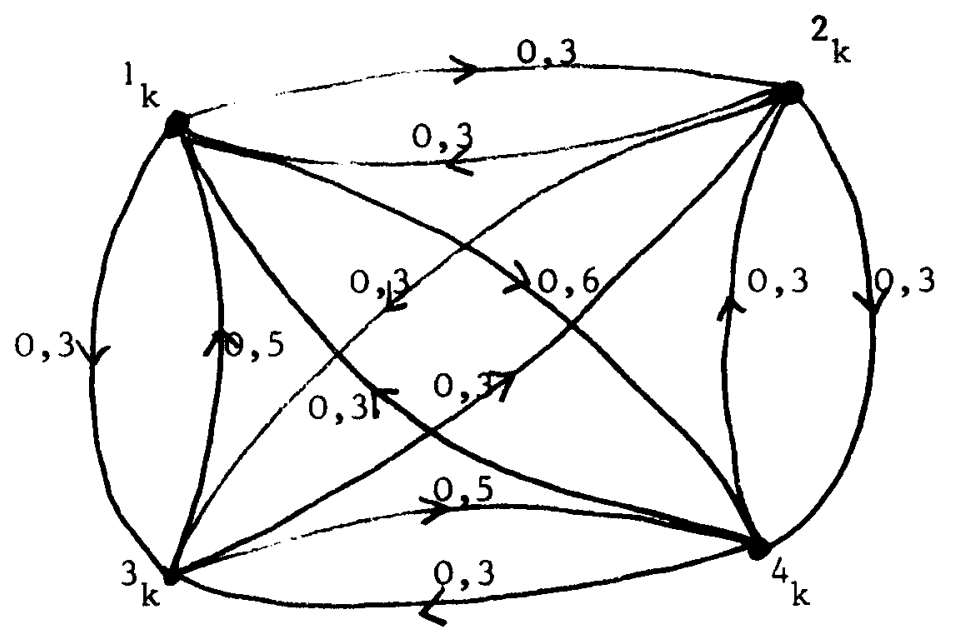

(for simplification's sake the loops have been left out of the graph)

The Max-Min transitivity property is verified. Buthfuzzy indifference is not congruent on the right relative torstrong preference. For example one has:

$$
{ }^{1} \succ^{4} k \text { et }{ }^{4} k \sim^{2} k \Rightarrow 1_{k} \succ^{2} k
$$

Similarly, fuzzy indifference is not congruent on the left relative the thistrong preference. We have for example:

Remark.

$$
\left.{ }^{2} k \sim{ }^{3} k \text { et } 3_{k}\right\rangle^{1_{k}} \Rightarrow{ }^{2} \zeta^{1_{k}}
$$

It is recalled that the above numbers are not measures of utility. A non numerical membership set suffices (see (11)). 
42 - The conditions (1) and (2) imposed on the structure (K, $y$ ) can be illustrated by the following example:

\begin{tabular}{|c|c|c|c|c|c|c|}
\multicolumn{1}{c}{} & \multicolumn{1}{c}{$1_{k}$} & ${ }^{2}{ }_{k}$ & $3_{k}$ & ${ }^{4} k$ & $5_{k}$ & $6_{k}$ \\
\cline { 2 - 8 } $1_{k}$ & 1 & 0,5 & 0,5 & 0,5 & 0,5 & 0,5 \\
\hline $2_{k}$ & 0,5 & 1 & 0,5 & 0,5 & 0,5 & 0,5 \\
\hline $3_{k}$ & 0,6 & 0,9 & 1 & 0,6 & 0,6 & 0,6 \\
\cline { 2 - 7 } $4_{k}$ & 0,7 & 0,7 & 0,6 & 1 & 0,6 & 0,6 \\
\hline $5_{k}$ & 0,7 & 0,9 & 0,8 & 0,7 & 1 & 0,7 \\
\hline $6_{k}$ & 0,7 & 0,7 & 0,9 & 0,8 & 0,7 & 1 \\
\hline
\end{tabular}

(The similary classes (Block diagonal matrix) have been underlined)

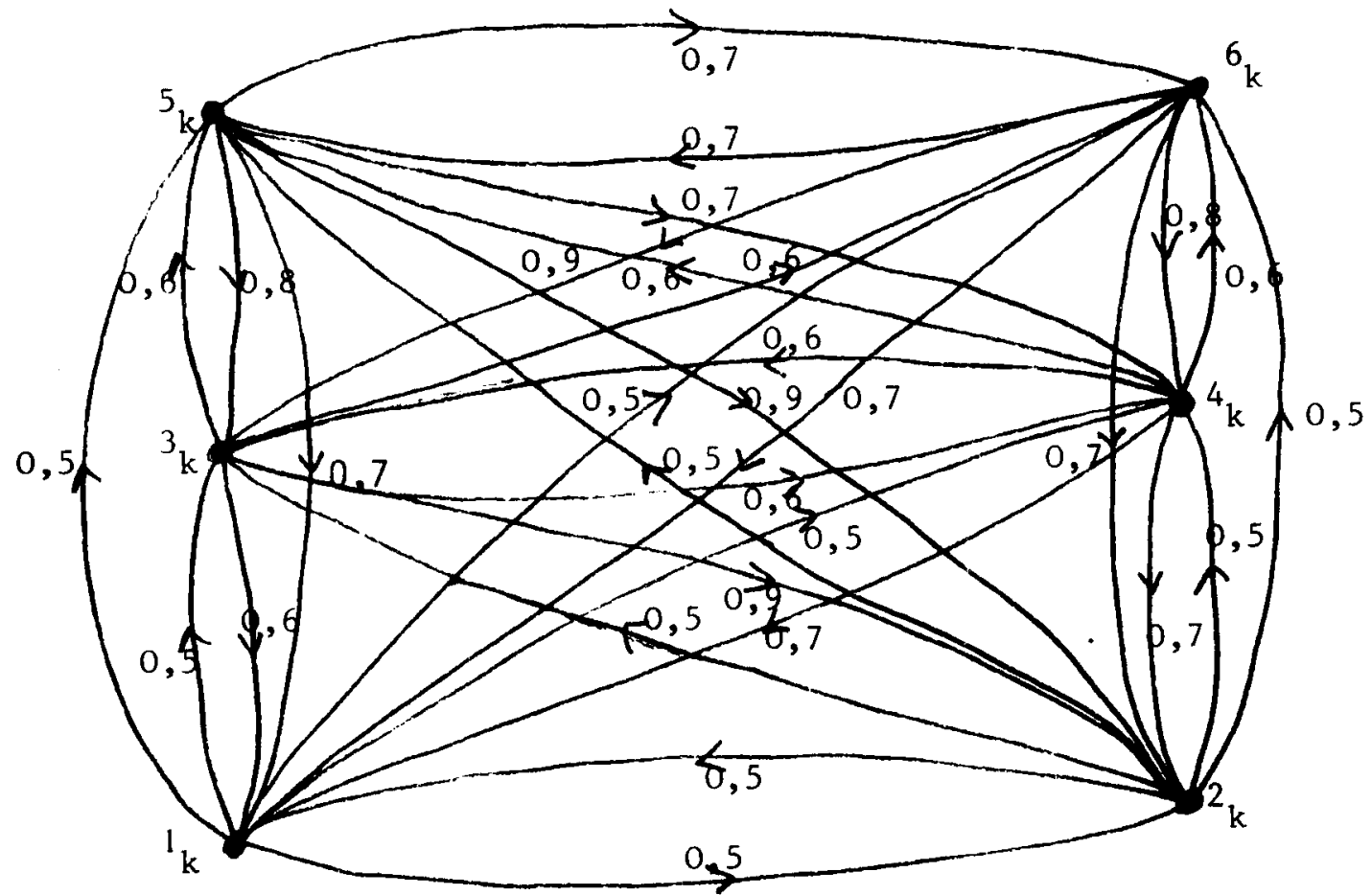

One can easily prove that:

1 - the fuzzy relation $\mathcal{R}$ is reflexive and Max-Min transitive (see (142))

2- the structure $(\underline{K}, \sim)$ is a fuzzy equivalence structure (see (143))

3- the structure $(\underline{k}, \geqslant)$ satisfies the properties of congruence on the right and left of indifference relative to strong preference (see (144)). 
5 - BIBLIOGRAPHY.

For an axiomatic approach to the classical theory of consumer behaviour see:

[1] AURAY (J.P.) DURU (G) MOUGEOT (M) - Problèmes d'économie mathématique (pages 10-84) Economica - Paris - 1977.

[2] DEBREU (G) - Theory of Value - John Wiley Sons - Inc. New-York. Traduction française: Théorie de la valeur (pages 53-79) - Dunod - Paris - 1966.

[3] GERARD-VARET (L.A.) PREVOT (M) THISSE (J.F.): Analyse mathématique pour 1 'économie. Topologie. (pages 33-43, 169-187, 205-219) - Dalloz - Paris - 1976.

[4] MALINVAUd (E): Leçons de théorie microéconomique (pages 10-37) - Dunod Paris - 1969.

[5] UZAWA (H) : Preference and Rational Choice in the Theory of Consumption Proceedings of a Symposium on Mathematical Methods in the Social Sciences - Stanford Stanford University Press - 1960.

[6] SCHEUBEL (J) Contribution à une théorie spatiale du consommateur. Thesis. University of Dijon. 1977 (to be published).

gives a synopsis of the elements, though still incomplete, of a spatial theory of consumer behaviour.

Finally the following may be regarded as basic works on the Mathematics of Fuzzy Subsets.

[7] KAUFMANN (A) Introduction à la théorie des sous-ensembles flous 4 Tomes (1973-1977) - Masson - Paris.

[8] PREVOT (M) Sous-ensembles flous - Volume 14 de la Collection de l'I.M.E. Sirey - Paris - 1977. 